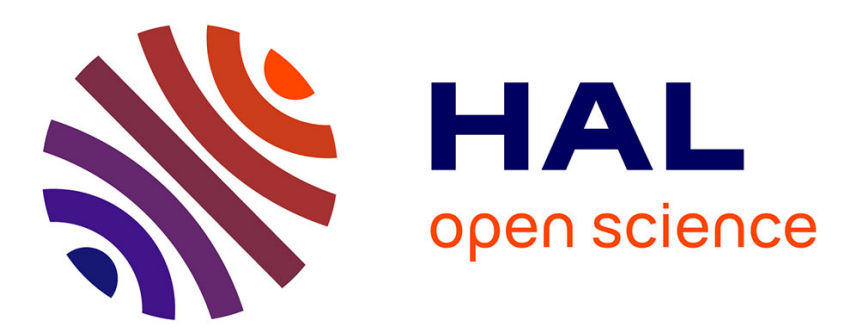

\title{
Effective mechanical properties of diaphyseal cortical bone in the canine femur
}

\author{
André Autefage, Sophie Palierne, Clémentine Charron, Pascal Swider
}

\section{To cite this version:}

André Autefage, Sophie Palierne, Clémentine Charron, Pascal Swider. Effective mechanical properties of diaphyseal cortical bone in the canine femur. Veterinary Journal, 2012, 194 (2), pp.202-209. 10.1016/j.tvjl.2012.04.001 . hal-01590755

\section{HAL Id: hal-01590755 https://hal.science/hal-01590755}

Submitted on 20 Sep 2017

HAL is a multi-disciplinary open access archive for the deposit and dissemination of scientific research documents, whether they are published or not. The documents may come from teaching and research institutions in France or abroad, or from public or private research centers.
L'archive ouverte pluridisciplinaire HAL, est destinée au dépôt et à la diffusion de documents scientifiques de niveau recherche, publiés ou non, émanant des établissements d'enseignement et de recherche français ou étrangers, des laboratoires publics ou privés. 


\section{Open Archive TOULOUSE Archive Ouverte (OATAO)}

OATAO is an open access repository that collects the work of Toulouse researchers and makes it freely available over the web where possible.

This is an author-deposited version published in : http://oatao.univ-toulouse.fr/ Eprints ID : 18177

To link to this article : DOI:10.1016/j.tvj1.2012.04.001

URL : http://dx.doi.org/10.1016/j.tvjl.2012.04.001

To cite this version : Autefage, André and Palierne, Sophie and Charron, Clémentine and Swider, Pascal Effective mechanical properties of diaphyseal cortical bone in the canine femur. (2012) The Veterinary Journal, vol. 194 ( $\mathrm{n}^{\circ}$ 2). pp. 202-209. ISSN 1090-0233

Any correspondence concerning this service should be sent to the repository administrator: staff-oatao@listes-diff.inp-toulouse.fr 


\title{
Effective mechanical properties of diaphyseal cortical bone in the canine femur
}

\author{
A. Autefage ${ }^{\mathrm{a}, *}$, S. Palierne ${ }^{\mathrm{a}}$, C. Charron ${ }^{\mathrm{a}}$, P. Swider ${ }^{\mathrm{b}}$ \\ ${ }^{a}$ Université de Toulouse, INP, École Nationale Vétérinaire de Toulouse, Unité de Recherche Clinique, Laboratoire de biomécanique, F-31076 Toulouse, France \\ ${ }^{\mathrm{b}}$ Université de Toulouse, IMFT UMR CNRS 5502, France
}

Keywords:

Bone mechanics

Canine femur

Experimental models

\begin{abstract}
A B S T R A C T
The effective elastic modulus, yield strength, yield strain, ultimate strength, ultimate strain, strain energy density at yield and strain energy density at ultimate failure of femoral diaphyseal cortical bone were investigated on canine femurs. Four femurs representative of the canine population were selected from four statistically-determined clusters based on increasing size and weight comprising the Toy poodle $(5 \mathrm{~kg})$, Poodle $(12 \mathrm{~kg})$, German shorthaired pointer $(25 \mathrm{~kg})$ and Doberman $(50 \mathrm{~kg})$. The zones of interest were the lateral, medial, cranial, and caudal quadrants of the mid-diaphysis. Effective mechanical properties were measured using quasi-static three-point bending tests on strips.

The averages \pm SD were 15.6 \pm 2.6 GPa for effective elastic modulus, $174.3 \pm 32.1$ MPa for yield strength, $0.012 \pm 0.003$ for yield strain, $251.0 \pm 49.1 \mathrm{MPa}$ for ultimate strength, $0.021 \pm 0.005$ for ultimate strain, $10.7 \pm 4.0 \mathrm{~J} \mathrm{~m}^{-3} \times 10^{5}$ for strain energy density at Yield and $33.0 \pm 14.1 \mathrm{~J} \mathrm{~m}^{-3} \times 10^{5}$ for strain energy density at ultimate failure. Significant differences were found between dogs and the effective elastic modulus increased with breed weight and size (13.9 GPa for the Toy poodle to $17.2 \mathrm{GPa}$ for the Doberman). The ultimate strength $\sigma_{u}$ and strain energy density at ultimate failure $U_{u}$ were significantly lower in the Toy poodle than in the Poodle and German shorthaired pointer indicating that the cortical bone material in the Toy poodle differed from that of the other dogs. Examination of the zones of interest revealed that the cranial quadrant showed the greatest stiffness, whereas strength was highest at the medial site. The caudal cortex was less stiff and strong than the cranial cortex.
\end{abstract}

\section{Introduction}

The choice of animal models in orthopaedic surgery remains open, particularly for the study of internal fixation implants or joint replacement. Among the animal species available, the canine model shows significant potential, especially for studying implant fixations (Daugaard et al., 2008; Kenner et al., 1979; Paul and Bargar, 1986; Skurla et al., 2005; Søballe et al., 1992; Vestermark et al., 2004).

Canine femoral morphology exhibits significant variability. The canine population can be segmented into four clusters on the basis of femoral morphological properties (Palierne, 2006; Palierne et al., 2008). It can be reasonably assumed that the geometric and mechanical properties interact to adapt to the size, weight, and dynamic activity of the animal.

The most relevant parameter for characterising first order mechanical properties is the longitudinal elastic modulus or Young's modulus. In the case of canine bones, interesting studies have reported the properties of cancellous and cortical bone but without clearly distinguishing their macroscopic morphological

\footnotetext{
* Corresponding author. Tel.: +33 561193852

E-mail address: a.autefage@envt.fr (A. Autefage).
}

characteristics (Behrens et al., 2006; Boutros et al., 2000; Kenner et al., 1979; Romanus, 1974; Vahey et al., 1987). Given the range of canine morphology, there is no evidence that the diaphyseal femoral cortices of dogs of different size and shape exhibit similar mechanical properties. Furthermore, some studies of murine femurs have shown potential correlations between genetic variations, bone morphology and mechanical properties (Wergedal et al., 2005).

Apart from breed-dependent variability, mechanical properties were also found to depend on the zone of interest. However, despite a large number of studies the results are conflicting. Markel et al. (1994) showed in the dog that the mineral density of cranial cortical bone was significantly higher than that of caudal bone in the proximal part of the diaphysis. The opposite was shown in the distal part of the diaphysis. These differences were corroborated by other studies of both animal and human femurs. The greatest strength or Young's modulus was observed in the lateral quadrant of canine femurs (Kenner et al., 1979) and human femurs (Evans and Lebow, 1951) and in the medial quadrant of other mammals and birds (Spatz et al., 1996). On the other hand, no significant difference was found between measurements of the Young's modulus in lateral, medial, cranial or caudal sites in human femurs (Cuppone et al., 2004). 
In this study, we hypothesised that the mechanical properties of the canine femur would be dependent on femoral morphology and the zone of interest. We examined the diaphyseal cortical bone of four femurs representative of the canine population and four zones of interest, namely the lateral, medial, cranial and caudal sites. Measurements were made of the effective elastic modulus, yield strength, yield strain, ultimate strength, ultimate strain, strain energy density at yield and strain energy density at ultimate.

\section{Materials and methods}

\section{Specimen preparation}

Sixty-two femurs were harvested from adult dogs and four of these were selected. The selected femurs were representative of each of four clusters detected in the adult canine population in a previous statistical study (Palierne et al. 2008). Twenty-four morphological parameters were examined as presented in Table 1 . For each of these morphological parameters, the difference between the candidate femur and the generic femur of each cluster (1-4) was calculated. The distribution of these differences was compared using a $z$-test with a standard Gaussian distribution. The femur was selected as representative of the cluster when the differences were not significant. The four dogs finally selected were: Toy poodle, 14 years old weighing $5 \mathrm{~kg}$; Poodle, 10 years old weighing $12 \mathrm{~kg}$; German shorthaired pointer, 13 years old weighing $25 \mathrm{~kg}$, and a Doberman pinscher, 7 years old weighing $50 \mathrm{~kg}$.

The femurs were harvested from adult dogs, which had been euthanased for medical reasons unrelated to orthopaedic conditions. Skeletally immature dogs and specimens showing evidence of traumatic or neoplastic osseous pathology were excluded from the study. The bones were cleaned of soft tissue and radiographed (Fig. 1a) to measure morphological parameters. The epiphysis and metaphysis of each femur were cut off but the femoral diaphysis was kept intact. The bone marrow was removed. The diaphyses were wrapped in saline-soaked gauze and frozen at $-20{ }^{\circ} \mathrm{C}$ for a storage period of $<6$ months.

The bones were thawed at room temperature and kept moist with saline soaked sponges while specimens were prepared for mechanical measurements. Between each step of the preparation, the specimens were submerged in saline solution in individual tubes. Rectilinear parallelepiped specimens were harvested from the middle of the femoral diaphysis as shown in Fig. 1b and c. The regions of interest were the cranial, caudal, medial and lateral cortical bones. Assuming that the cortical bone was transversely isotropic, the long axis of the specimens coincided with the principal axis of material properties and the cross-section of the strip was located in the transversely isotropic plane of the diaphyseal cortical bone.

As shown in Fig. 2a, cuts were made in the latero-medial plane of the four bones and in the cranio-caudal plane only for the Poodle and German shorthaired pointer bones using a precision diamond saw (Isomet 1000, Buehler) with constant water- cooling. Depending on the bone stock, two to six specimens with a minimum length of $20 \mathrm{~mm}$ were obtained from each femur. The distribution of the harvested specimens in each quadrant for each femur is given in Table 2.

The cancellous bone remaining on surfaces facing the medullar canal was removed with a scalpel under surgical microscope. Each specimen was identified, orientated and measured with callipers accurate to $20 \mu \mathrm{m}$ and placed in saline solution. The specimen width was measured at each end and at one- and two-thirds of the length. The mean of these four measurements was taken as the width of the specimen. Finally, the mean \pm SD dimensions of the specimen database were as follows: thickness, $t=1.08 \pm 0.29 \mathrm{~mm}$ (range $0.56-1.52 \mathrm{~mm}$ ); width, $w=2.25 \pm 0.49 \mathrm{~mm}$ (range $1.32-3.01 \mathrm{~mm}$ ), and length, $l=28.91 \pm 2.69 \mathrm{~mm}$ (range $20-30 \mathrm{~mm})$. The span-to-thickness ratio $(28.42 \pm 6.40)$ was between 19.74 and 46.43 .

\section{Measurement protocol}

The mechanical properties of the specimens were determined by three-point bending tests as shown in Fig. 2b. The experiments were conducted on a tensile machine (10 MH, MTS). The specimen was simply supported on a fixture, the span of which varied from 20 to $30 \mathrm{~mm}$ depending on the specimen length. The cranial and caudal specimens were subjected to bending in a lateral-medial direction while the lateral and medial specimens were subjected to bending in a cranial-caudal direction.

Each specimen was subjected to three loading/unloading cycles with a displacement control, staying within the linear-elastic domain according to previous tests performed on pre-test specimens. The fourth and final test culminated in specimen fracture. The contribution of bone viscoelastic properties to the quasi-static response of the specimen was suppressed by fixing the displacement rate at $0.1 \mathrm{~mm} / \mathrm{min}$. Force and displacement acquisition were done at $10 \mathrm{~Hz}$ (software Testwork 4.08B, MTS). Measurements were taken at room temperature and the specimens were kept moist with saline solution.

The influence of shear was negligible and the unidirectional stress field $\sigma$ was described by Eq. (1), involving the normal strain field $\varepsilon$ and the effective modulus E (Turner and Burr, 2001):

$\sigma=E \varepsilon \quad$ with $\sigma=\frac{3 F I_{s}}{2 w t^{2}} \quad$ and $\quad \varepsilon=\frac{6 t d}{l_{s}^{2}}$

where $F$ is the transverse force $F$ applied to the specimen $(\mathrm{N}) ; l_{s}$ is the experimental span $(\mathrm{m}) ; w$, specimen width $(\mathrm{m}) ; t$, specimen thickness $(\mathrm{m}) ; d$, actuator displacement $(\mathrm{m})$.

Eq. (1) was used to obtain $E$ from the stress-strain experimental curves by applying a linear regression to the linear domain of the static response of the specimen. The yield point, that is the transition to the plastic domain, was determined when the value predicted by the previous linear regression was exactly $10 \%$ greater than the experimental data. The ultimate strength and the ultimate strain were measured just before fracture. Fig. 2c shows the measurement methods of the effec-

Table 1

Morphological parameters of the selected femurs.

\begin{tabular}{|c|c|c|c|c|c|c|c|c|}
\hline & Cluster 1 & $\mathrm{~T}$ & Cluster 2 & $\mathrm{P}$ & Cluster 3 & GSP & Cluster 4 & $\mathrm{D}$ \\
\hline Intertrochanteric distance (mm) & 19.6 & 17.0 & 23.4 & 24.0 & 32.7 & 31.0 & 37.9 & 39.0 \\
\hline Mediolateral head offset ( $\mathrm{mm})$ & 9.5 & 9.0 & 11.0 & 12.0 & 14.9 & 14.0 & 17.2 & 17.0 \\
\hline Cranio-caudal femoral head diameter (mm) & 12.9 & 11.0 & 16.0 & 15.0 & 21.5 & 21.0 & 25.1 & 25.0 \\
\hline Mediolateral femoral head diameter (mm) & 12.6 & 11.5 & 15.7 & 15.0 & 21.5 & 21.0 & 25.3 & 25.5 \\
\hline Head position (mm) & 12.2 & 11.0 & 15.7 & 17.0 & 23.2 & 23.5 & 28.3 & 28.0 \\
\hline Intra-cortical width (lesser trochanter) (mm) & 8.1 & 7.0 & 12.8 & 10.0 & 19.7 & 19.0 & 25.9 & 23.0 \\
\hline Intra-cortical width (prox. lesser trochanter) (mm) & 9.9 & 9.0 & 15.5 & 13.0 & 23.2 & 22.0 & 29.5 & 28.0 \\
\hline Intra-cortical width (distal lesser trochanter) (mm) & 6.9 & 5.5 & 11.2 & 9.0 & 17.7 & 17.0 & 23.3 & 21.0 \\
\hline Mediolateral medullar width (isthmus) (mm) & 4.5 & 4.0 & 6.5 & 6.0 & 9.2 & 8.5 & 12.7 & 11.0 \\
\hline Mediolateral extra-cortical width (isthmus) (mm) & 8.3 & 7.5 & 10.9 & 11.0 & 14.5 & 13.0 & 18.2 & 17.0 \\
\hline Proximal location of the femoral isthmus (mm) & 17.1 & 17.0 & 28.1 & 29.5 & 42.7 & 45.5 & 52.7 & 52.0 \\
\hline Distal location of the femoral isthmus (mm) & 29.1 & 33.5 & 40.2 & 41.0 & 55.9 & 59.0 & 68.4 & 69.0 \\
\hline Cervico-diaphyseal angle $\left(^{\circ}\right)$ & 135.6 & 134.0 & 141.0 & 141.0 & 144.3 & 145.0 & 147.3 & 148.0 \\
\hline Length of femoral neck (mm) & 11.9 & 11.5 & 15.2 & 16.0 & 20.7 & 19.5 & 25.3 & 24.5 \\
\hline Total length of the femur (mm) & 104.3 & 103.0 & 138.0 & 143.0 & 198.2 & 190.5 & 234.9 & 234.0 \\
\hline Craniocaudal medullar width (isthmus) (mm) & 3.7 & 3.0 & 6.1 & 5.0 & 9.8 & 10.0 & 13.9 & 13.0 \\
\hline Craniocaudal extra-cortical width (isthmus) (mm) & 7.5 & 7.0 & 10.4 & 10.0 & 15.2 & 15.0 & 19.4 & 18.5 \\
\hline Cranio-caudal head offset $(\mathrm{mm})$ & 4.4 & 4.0 & 6.2 & 7.0 & 9.3 & 7.0 & 9.6 & 11.0 \\
\hline Canal flare index & 2.2 & 2.2 & 2.4 & 2.2 & 2.6 & 2.6 & 2.4 & 2.6 \\
\hline Metaphyseal canal flare index & 1.4 & 1.6 & 1.4 & 1.4 & 1.3 & 1.3 & 1.3 & 1.3 \\
\hline Femoral head and neck anteversion angle $\left({ }^{\circ}\right)$ & 24.8 & 23.9 & 29.1 & 30.3 & 32.0 & 26.6 & 28.9 & 33.0 \\
\hline Cortico-medullar index & 0.4 & 0.5 & 0.4 & 0.5 & 0.4 & 0.3 & 0.3 & 0.3 \\
\hline Index of proximal position of the isthmus & 35.3 & 33.0 & 37.4 & 37.4 & 38.0 & 40.2 & 38.6 & 38.9 \\
\hline Index of distal position of the isthmus & 46.9 & 49.0 & 46.2 & 45.5 & 44.7 & 47.2 & 45.2 & 46.2 \\
\hline
\end{tabular}

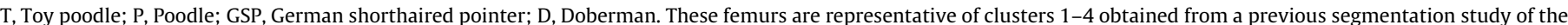
canine population (Palierne et al., 2008). 


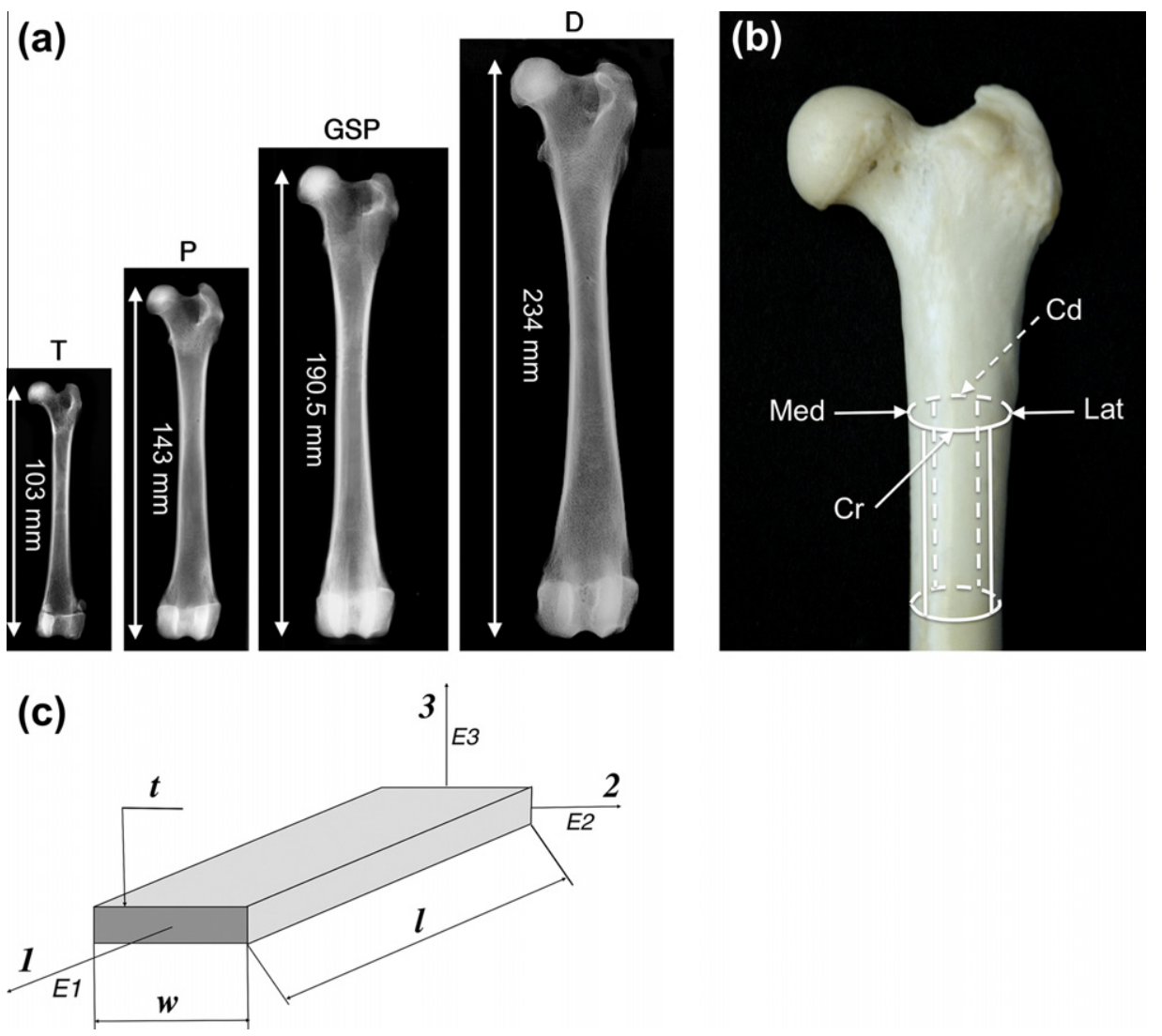

Fig. 1. (a) Craniocaudal X-rays of femurs of Toy poodle, T; Poodle, P; German shorthaired pointer, GSP; and Doberman, D. (b) Specimens were harvested from each quarters of the femoral diaphysis. Cr, cranial site; Cd, caudal site; Lat, lateral site; Med, medial site. (c) Size of specimens: width, $w(2.25 \pm 0.49 \mathrm{~mm})$; thickness, $t(1.08 \pm 0.29 \mathrm{~mm})$, length, $l(28.91 \pm 2.69 \mathrm{~mm})$. The cross-section was in the assumed transversely isotropic plane $(1,2,3)$ of diaphyseal cortical bone. E1, E2 and E3 are Young's moduli.
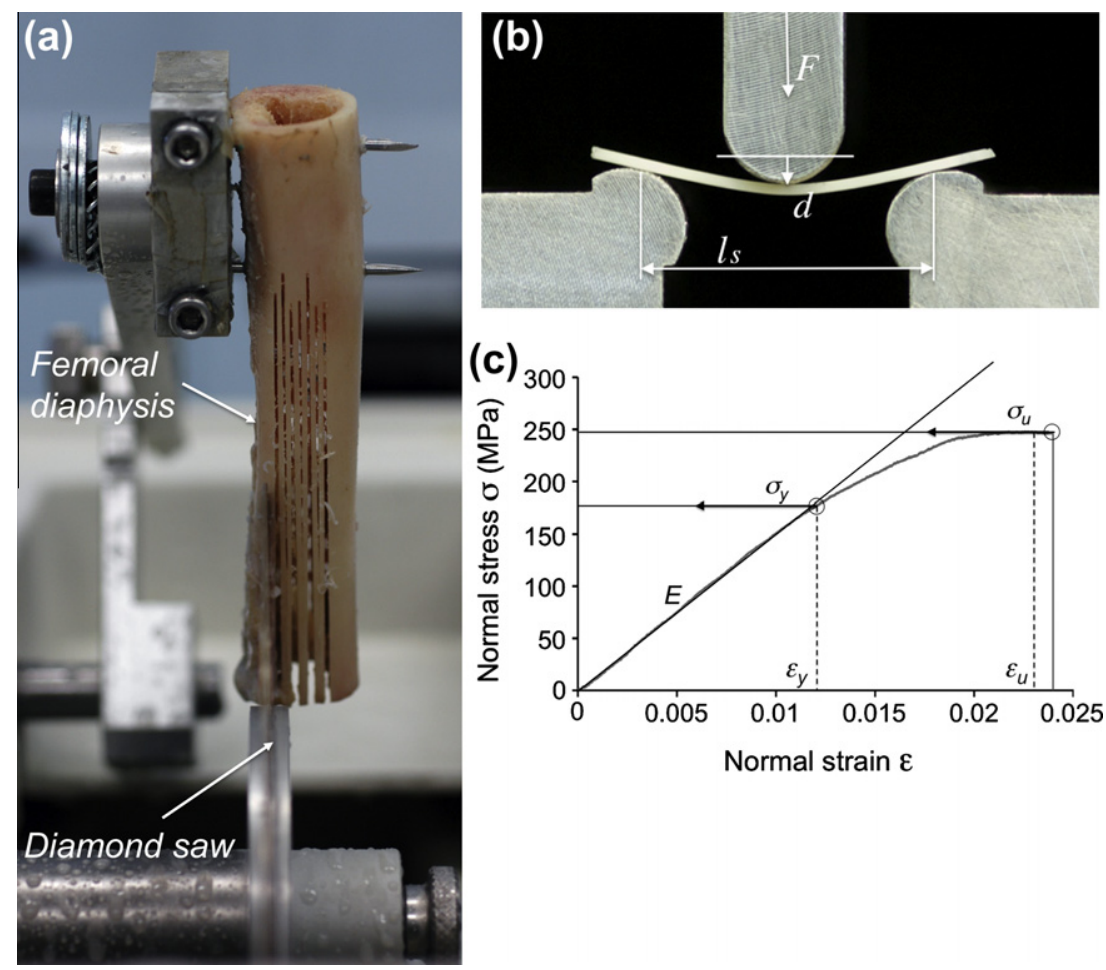

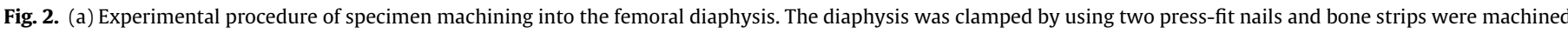

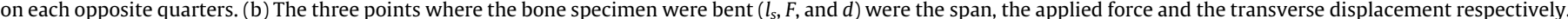

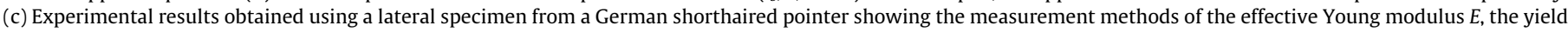
strength $\sigma_{y}$, the yield strain $\varepsilon_{y}$, the ultimate strength $\sigma_{u}$ and the ultimate strain $\varepsilon_{u}$. 
Table 2

Distribution of the cortical bone specimens.

\begin{tabular}{|c|c|c|c|c|c|}
\hline \multirow[t]{2}{*}{ Dogs } & \multicolumn{5}{|l|}{ Sites } \\
\hline & Lateral & Medial & Cranial & Caudal & Total \\
\hline Toy poodle ( $5 \mathrm{~kg} ; 14$ years old) & 4 & 4 & 0 & 0 & 8 \\
\hline Poodle ( $12 \mathrm{~kg} ; 10$ years old) & 2 & 3 & 3 & 3 & 11 \\
\hline German Shorthaired Pointer ( $25 \mathrm{~kg}$; 13 years old) & 2 & 4 & 5 & 4 & 15 \\
\hline Doberman (50 kg; 7 years old) & 6 & 6 & 0 & 0 & 12 \\
\hline Total & 14 & 17 & 8 & 7 & 46 \\
\hline
\end{tabular}

tive Young's modulus $E$, the yield strength $\sigma_{y}$, the yield strain $\varepsilon_{y}$, the ultimate strength $\sigma_{u}$ and the ultimate strain $\varepsilon_{u}$ on a representative specimen. The area under the curves at the yield point and ultimate strength were used to obtain the strain energy density at yield $U_{y}$ and strain energy density at ultimate failure $U_{u}$, respectively. The strain rate was calculated for each specimen from the ratio ultimate strain - time(s) necessary to obtain ultimate strength.

Young's modulus, yield strength and ultimate strength were corrected to a strain rate of $0.00001 / \mathrm{s}$ using empirical relationships between stiffness and strain rate and strength and strain rate, from Carter and Hayes (Carter and Hayes, 1976 1977). The relationship between effective elastic modulus and specimen size strength and stiffness, corrected strength and corrected stiffness, Young's modulus, strength and strain rate were examined using linear regressions. For the mechanical parameters, the statistical analysis consisted of a two-way analysis of variance ANOVA with two factors (dogs and sites) followed by Tukey's test. Statistical significance was defined as $P<0.05$.

\section{Results}

The effective Young's modulus $E$, yield strength $\sigma_{y}$, yield strain $\varepsilon_{y}$, ultimate strength $\sigma_{u}$, ultimate strain $\varepsilon_{u}$, strain energy density at yield $U_{y}$ and strain energy density at ultimate failure $U_{u}$ for the Toy poodle, Poodle, German shorthaired pointer and Doberman are reported in Table 3 and Fig. 3. The results of the statistical analysis of mechanical parameters for each dog and each site are reported in Table 4 . The strain rate ranged from $0.89 \times 10^{-5} / \mathrm{s}$ to $2.00 \times 10^{-5} / \mathrm{s}$ (mean $\left.\pm \mathrm{SD}, 1.29 \pm 0.29 \times 10^{-5} / \mathrm{s}\right)$.

The mean \pm SD values for Young's modulus $E$, yield strength $\sigma_{y}$ and ultimate strength $\sigma_{u}$ were $\mathrm{E}=15.6 \pm 2.6 \mathrm{GPa}$, $\sigma_{y}=174.3 \pm 32.1 \mathrm{MPa}$ and $\sigma_{u}=251.0 \pm 49.2 \mathrm{MPa}$ respectively. The effective Young's modulus $E$ increased with dog size from 13.86 to $17.21 \mathrm{GPa}$. The differences between all dogs were statistically significant $(P<0.05)$ except between the Poodle and the German shorthaired pointer, as detailed in Table 4 . For yield strength $\sigma_{y}$, a significant difference $(P=0.033)$ was only observed between the Poodle and the German shorthaired pointer. For ultimate strength $\sigma_{u}$, significant differences were obtained between the
Toy poodle and the Poodle $(P=0.016)$ and between the Toy poodle and the German shorthaired pointer $(P=0.013)$.

The average yield strain $\varepsilon_{y}$ and ultimate strain $\varepsilon_{u}$ were $0.0094 \pm 0.0013$ and $0.017 \pm 0.002$ respectively. The yield strain $\varepsilon_{y}$ and ultimate strain $\varepsilon_{u}$ for Toy poodle were significantly greater $(P<0.001)$ than for the three other dogs (Tables 3 and 4$)$. The strain energy density at yield $U_{y}$ ranged from $8.5 \pm 3.1 \mathrm{~J} \mathrm{~m}^{-3} \times 10^{5}$ for the German shorthaired pointer to $15.0 \pm 4.1 \mathrm{~J} \mathrm{~m}^{-3} \times 10^{5}$ for the Toy poodle. A significant difference was observed between the Toy poodle and the three other dogs $(P \leqslant 0.002)$. The strain energy density at ultimate failure $U_{u}$ for the Toy poodle was significantly greater than for the Poodle $(P=0.002)$ and German shorthaired pointer $(P=0.001)$ (Tables 3 and 4$)$.

The variation in bone mechanical properties with regard to the zones of interest in the diaphysis was investigated by averaging the data from the four femurs according to site. Results for the lateral, medial, cranial and caudal sites are reported in Table 3 and Fig. 3.

The effective Young's modulus $E$ of the cranial site $(18.0 \pm 2.3 \mathrm{GPa})$ was significantly greater than that of the lateral site $(14.5 \pm 2.5 \mathrm{GPa})$, medial site $(15.3 \pm 2.5 \mathrm{GPa})$ and caudal site $(14.6 \pm 1.0 \mathrm{GPa})$ (Table 4).

Two main results were observed for bone strength. Firstly, the yield strength $\sigma_{y}$ of caudal sites was significantly lower than that of medial sites (Tables 3 and 4). Secondly, the ultimate strength $\sigma_{u}$ of the caudal site was significantly lower than that of the medial and cranial sites. The strain energy density at yield $U_{y}$ and the strain energy density at ultimate failure $U_{u}$ were significantly lower for the caudal than for the medial site (Tables 3 and 4).

The differences between measured values and corrected values for Young's modulus, yield strength and ultimate strength were minimal ( $1.4 \pm 1.3 \%$, range: $0.003-4.07 \%$; Tables 3 and 4$)$. The corrected Young's modulus for a strain rate of $0.00001 / \mathrm{s}$ was significantly lower $(P=0.02)$ for the Toy poodle $(13.8 \pm 3.3 \mathrm{GPa})$ than

Table 3

Least square means of the mechanical parameters.

\begin{tabular}{|c|c|c|c|c|c|c|c|c|c|c|c|}
\hline Dogs & Sites & $E(\mathrm{GPa})$ & $E \operatorname{cor}(\mathrm{GPa})$ & $\sigma_{y}(\mathrm{MPa})$ & $\sigma_{y} \operatorname{cor}(\mathrm{MPa})$ & $\varepsilon_{y}$ & $\sigma(\mathrm{MPa})$ & $\sigma_{u} \operatorname{cor}(\mathrm{MPa})$ & $\varepsilon_{u}$ & $U_{y}\left(\mathrm{~J} \mathrm{~m}^{-3} \times 10^{5}\right)$ & $U_{u}\left(\mathrm{~J} \mathrm{~m}^{-3} \times 10^{5}\right)$ \\
\hline \multirow[t]{2}{*}{$\mathrm{T}$} & Lateral $(n=4)$ & 12.62 & 12.89 & 182.66 & 181.41 & 0.0142 & 261.44 & 255.25 & 0.0260 & 13.67 & 41.76 \\
\hline & Medial $(n=4)$ & 13.68 & 13.70 & 219.05 & 213.66 & 0.0164 & 336.10 & 309.42 & 0.0302 & 18.74 & 57.45 \\
\hline \multirow[t]{4}{*}{$P$} & Lateral $(n=2)$ & 12.84 & 12.45 & 153.41 & 151.87 & 0.0124 & 200.53 & 198.19 & 0.0176 & 10.00 & 20.71 \\
\hline & Medial $(n=3)$ & 15.63 & 15.31 & 170.07 & 170.15 & 0.0113 & 246.29 & 246.35 & 0.0230 & 9.86 & 35.22 \\
\hline & Cranial $(n=3)$ & 17.46 & 16.99 & 171.38 & 166.59 & 0.0099 & 252.22 & 245.19 & 0.0196 & 8.66 & 30.07 \\
\hline & Caudal $(n=3)$ & 15.24 & 14.78 & 148.81 & 144.57 & 0.0097 & 195.14 & 189.58 & 0.0149 & 7.54 & 16.88 \\
\hline \multirow[t]{4}{*}{ GSP } & Lateral $(n=2)$ & 16.27 & 16.18 & 177.11 & 176.75 & 0.0113 & 254.99 & 254.50 & 0.0211 & 10.11 & 31.90 \\
\hline & Medial $(n=4)$ & 15.25 & 15.22 & 178.74 & 177.95 & 0.0121 & 247.05 & 245.91 & 0.0225 & 11.19 & 31.57 \\
\hline & Cranial $(n=5)$ & 18.59 & 17.52 & 163.02 & 158.24 & 0.0091 & 232.48 & 225.69 & 0.0154 & 7.67 & 20.80 \\
\hline & Caudal $(n=4)$ & 14.29 & 13.81 & 124.42 & 121.06 & 0.0088 & 183.73 & 178.74 & 0.0162 & 5.72 & 17.86 \\
\hline \multirow[t]{2}{*}{$\mathrm{D}$} & Lateral $(n=6)$ & 16.27 & 16.29 & 184.36 & 183.49 & 0.0113 & 274.18 & 269.42 & 0.0227 & 10.94 & 38.11 \\
\hline & Medial $(n=6)$ & 16.75 & 16.43 & 201.66 & 201.06 & 0.0123 & 279.31 & 278.46 & 0.0235 & 12.76 & 40.62 \\
\hline
\end{tabular}

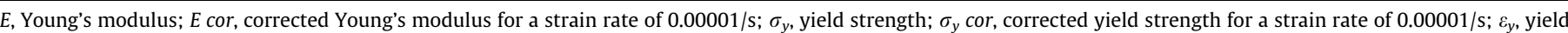

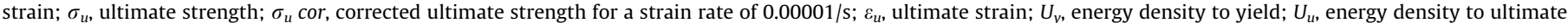
failure; T, Toy poodle; P, Poodle; GSP, German shorthaired pointer; D, Doberman. The number of specimens is indicated in brackets. 

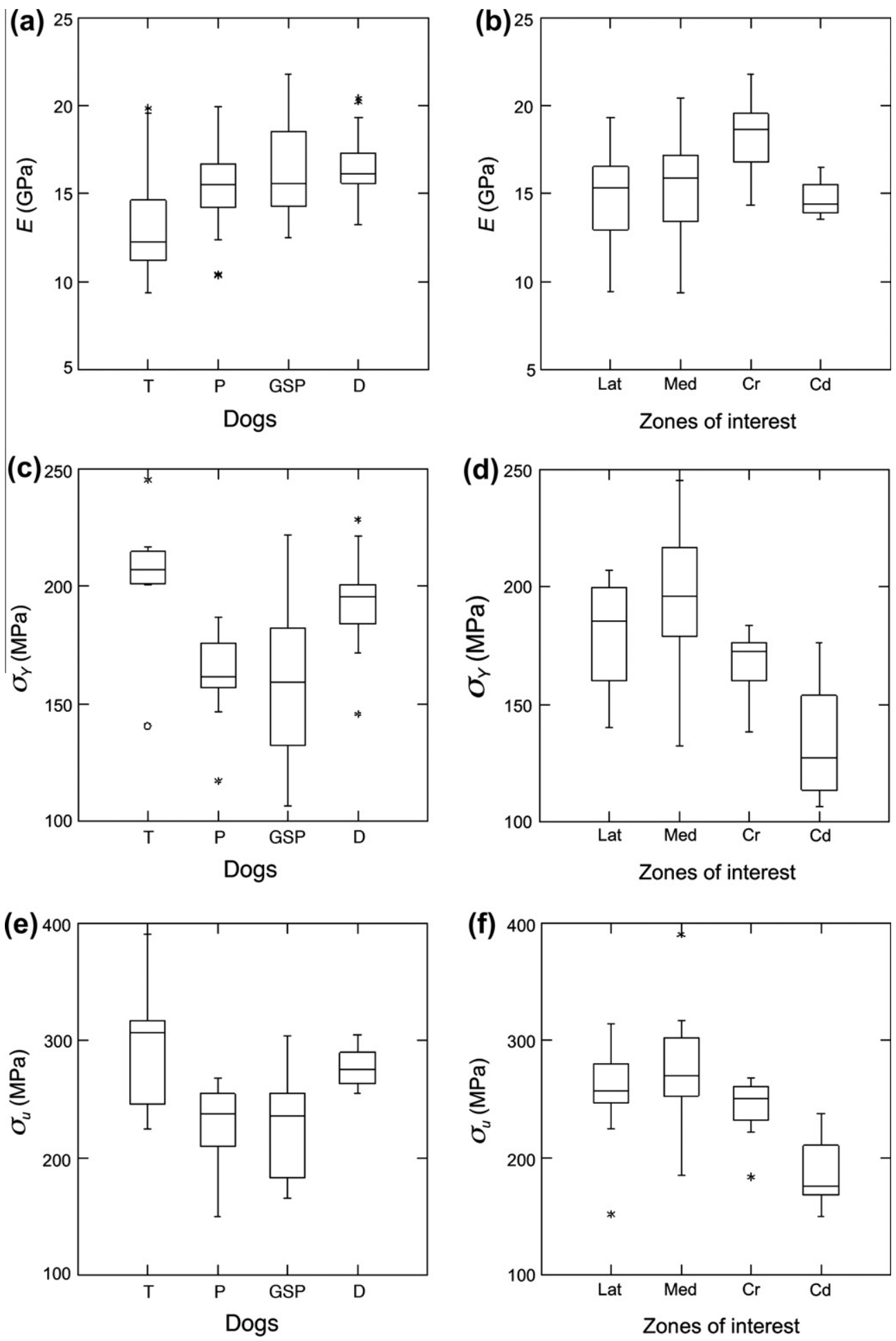

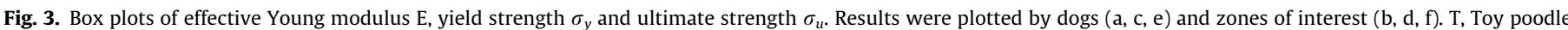

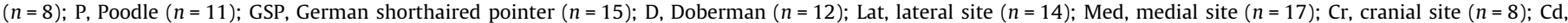
caudal site $(n=7)$. The number of specimens is indicated in brackets. The asterisks represent the outliers.

for the Doberman $(16.8 \pm 1.3 \mathrm{GPa})$. The corrected Young's modulus was significantly lower $(P=0.04)$ for the caudal $(14.2 \pm 1.0 \mathrm{GPa})$ than for the cranial site $(17.3 \pm 2.0 \mathrm{GPa})$. The corrected yield and ultimate strengths were significantly lower for the caudal than for the medial site $(P=0.001$ and 0.007 , respectively).

There was a significant linear relation between Young's modulus $E$ and specimen width $\left(P=0.01, r^{2}=0.14\right)$ and specimen thickness $\left(P=0.003, \quad r^{2}=0.11\right)$. On the other hand, no relationship was found between the effective elastic modulus $E$ and strain rate $(P=0.99)$ or between ultimate strength $\sigma_{u}$ and strain rate $(P=0.14)$. However, a strong relationship was found between ultimate strength and Young's modulus $\left(P=0.000, \quad r^{2}=0.27\right)$ as well as between corrected ultimate strength and corrected Young's modulus $(P=0.000$, $\left.r^{2}=0.30\right)$. 
Table 4

Results of ANOVA ( $P$ values).

\begin{tabular}{|c|c|c|c|c|c|c|c|c|c|c|c|}
\hline & Comparisons & $E(\mathrm{GPa})$ & $E \operatorname{cor}(\mathrm{GPa})$ & $\sigma_{y}(\mathrm{MPa})$ & $\sigma_{y} \operatorname{cor}(\mathrm{MPa})$ & $\varepsilon_{y}$ & $\sigma_{u}(\mathrm{MPa})$ & $\sigma_{u} \operatorname{cor}(\mathrm{MPa})$ & $\varepsilon_{u}$ & $U_{y}\left(\mathrm{~J} \mathrm{~m}^{-3} \times 10^{5}\right)$ & $U_{u}\left(\mathrm{~J} \mathrm{~m}^{-3} \times 10^{5}\right)$ \\
\hline \multirow[t]{6}{*}{ Dogs } & $\mathrm{T}-\mathrm{P}$ & 0.017 & 0.646 & 0.070 & 0.107 & 0.001 & 0.016 & 0.076 & 0.000 & 0.000 & 0.002 \\
\hline & T-GSP & 0.000 & 0.364 & 0.033 & 0.055 & 0.000 & 0.013 & 0.070 & 0.000 & 0.000 & 0.001 \\
\hline & T-D & 0.000 & 0.017 & 0.847 & 0.940 & 0.000 & 0.585 & 0.931 & 0.004 & 0.002 & 0.087 \\
\hline & P-GSP & 0.577 & 0.940 & 0.987 & 0.989 & 0.876 & 1.000 & 0.999 & 0.990 & 0.968 & 0.978 \\
\hline & P-D & 0.001 & 0.270 & 0.195 & 0.187 & 0.997 & 0.113 & 0.142 & 0.572 & 0.561 & 0.205 \\
\hline & GSP-D & 0.032 & 0.507 & 0.097 & 0.095 & 0.968 & 0.099 & 0.130 & 0.388 & 0.312 & 0.091 \\
\hline \multirow[t]{6}{*}{ Sites } & L-M & 0.188 & 0.877 & 0.136 & 0.149 & 0.464 & 0.253 & 0.332 & 0.115 & 0.090 & 0.182 \\
\hline & $\mathrm{L}-\mathrm{Cr}$ & 0.000 & 0.079 & 0.933 & 0.996 & 0.203 & 0.801 & 0.957 & 0.339 & 0.886 & 0.994 \\
\hline & $\mathrm{L}-\mathrm{Cd}$ & 0.999 & 0.990 & 0.232 & 0.129 & 0.107 & 0.286 & 0.190 & 0.051 & 0.220 & 0.333 \\
\hline & $\mathrm{M}-\mathrm{Cr}$ & 0.000 & 0.167 & 0.747 & 0.530 & 0.013 & 0.967 & 0.887 & 0.006 & 0.065 & 0.289 \\
\hline & $\mathrm{M}-\mathrm{Cd}$ & 0.540 & 0.813 & 0.004 & 0.001 & 0.005 & 0.009 & 0.007 & 0.000 & 0.002 & 0.009 \\
\hline & $\mathrm{Cr}-\mathrm{Cd}$ & 0.000 & 0.037 & 0.069 & 0.077 & 0.987 & 0.044 & 0.066 & 0.753 & 0.602 & 0.466 \\
\hline
\end{tabular}

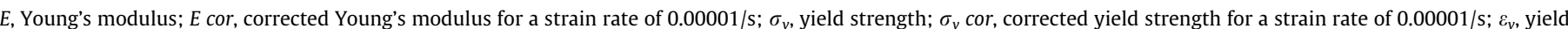

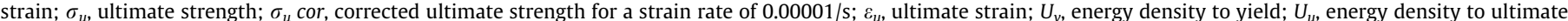
failure; T, Toy poodle; P, Poodle; GSP, German shorthaired pointer; D, Doberman; L, lateral; M, medial; Cr, cranial; Cd, caudal.

\section{Discussion}

We initially hypothesised that the mechanical properties of diaphyseal cortical bone from the canine femur would be dependent on dog size and the zone of interest. We investigated this hypothesis by studying four dogs representative of the canine population in terms of size and weight. Our assumptions were confirmed for Young's modulus E. The average effective Young's modulus was $15.6 \mathrm{GPa}$ with a range of 13.9-18.0 GPa depending on the dog and zone of interest. The average values for yield strength and ultimate strength were 174.3 MPa and 251.0 MPa, respectively. The differences linked to sites and dogs were between 149.4 and 193.1 MPa for yield strength and between 214.1 and 288.0 MPa for ultimate strength.

The canine population exhibits extremely large variations in weight and size. In previous studies we showed that the population could be segmented into four clusters, each represented by a generic femur (Palierne et al., 2008). As shown in Table 1, the four dogs selected for our experiments were morphometrically representative of these clusters. However, given that only one femur was tested for each cluster, much more work will be needed to extrapolate our results to the canine population as a whole.

Particular attention was paid to the storage of specimens. Adverse effects of dehydration (Turner and Burr, 1993) were avoided by keeping the specimens moist throughout the procedure: freezing and thawing in $\mathrm{NaCl}$-soaked gauzes, spraying during cutting, storage in saline solution and hydration between each mechanical test. The influence of temperature was considered minimal for our static tests (Turner and Burr, 1993). A maximum increase of $2-4 \%$ was observed for Young's modulus measured at room temperature when compared to tests at $37^{\circ} \mathrm{C}$ (Bonfield and Li, 1968; Bonfield and Tully, 1982; Smith and Walmsley, 1959).

A three-point bending test was used to characterise the effective mechanical properties of diaphyseal cortical bone. The geometry of the specimen was designed to cancel shear effects (Spatz et al., 1996). The ratio of length to thickness should be at least 20:1 to guarantee that the shear displacements are insignificant (Spatz et al., 1996). Therefore, a span-to-thickness ratio $>20$ was chosen (ratio $=28.4 \pm 6.4$ ) to maximally decrease the influence of shear. With a span-to-thickness of approximately 20, the calculated Young's modulus is within 95\% of the true Young's modulus of bone, which is an adequate approximation (Spatz et al., 1996). The displacement rate was low $(0.1 \mathrm{~mm} / \mathrm{min})$ to suppress the influence of bone viscoelasticity (Carter and Hayes, 1977; Lakes, 2004; Linde et al., 1991; Rice et al., 1988; Turner, 1993) and induced a very low strain rate $\left(1.29 \pm 0.29 \times 10^{-5} / \mathrm{s}\right)$ that did not influence the measurement of the main mechanical parameters.
In our study, no relationship was found between effective elastic modulus $E$ and strain rate or between ultimate strength $\sigma_{u}$ and strain rate. The width and thickness of the specimen had an influence on the measurement of Young's modulus $E$ as shown by the linear regression. However, the Pearson correlation coefficient ( 0.33 for width and 0.43 for thickness) did not show a strong correlation between elastic modulus and specimen size. Even though the relationships between Young's modulus and specimen size (width and thickness) were significant $(P<0.05)$, the squared multiple $R$-values were low ( 0.14 for width and 0.11 for thickness), indicating that width and thickness explain $14 \%$ and $11 \%$ of the variability of the elastic modulus, respectively. Each specimen was subjected to three loading/unloading cycles while the fourth and final test induced specimen fracture. During the first three loading/unloading cycles, the load was chosen to keep within the linear-elastic domain according to previous tests performed on pre-test specimens and was systematically lower than the yield point measured in the fourth test. Thus, we can assume that the first three tests did not cause enough damage to affect the effective modulus of subsequent tests.

Calculating the effective elastic modulus or Young's modulus was not particularly difficult since this parameter characterises the linear behaviour of the structure. The effective longitudinal modulus was investigated by assuming that the specimen was aligned with the principal direction of elasticity of the cortical bone in alignment with the diaphyseal axis. The architecture of the canine femoral diaphysis did not allow harvesting of strips in the transverse direction. In contrast, the yield strength was more difficult to measure as it represented a gradual transition towards plastic behaviour. The methods available, such as the offset method (Turner and Burr, 1993), rely on arbitrary criteria to detect this transition and generally involve large variability. Using the offset method with $0.2 \%$ strain, the yield point was $28 \%$ higher than the yield point determined in the current study (data not shown).

The elastic modulus of cortical bone obtained from longitudinal cross-section specimens showed wide variability. In the human femur, elastic modulus ranges from 9 to $20 \mathrm{GPa}$ (Bayraktar et al., 2004; Currey et al., 1997). In the bovine femur, values of about 18 GPa (Currey, 1988; Currey et al., 1995) have been obtained. In the rabbit femur, the range was 11-15 GPa (An et al., 1996; Ayers et al., 1996). In mice and rats the ranges were 3-11 GPa and 7$8 \mathrm{GPa}$, respectively (Barengolts et al., 1993; Jorgensen et al., 1991; Wergedal et al., 2005).

Some data have already been reported for canine femurs. An average value of $17 \mathrm{GPa}$ was obtained from tensile, bending and compressive tests (Behrens et al., 2006; Romanus, 1974). Our experiments gave a mean effective modulus of $15.6 \mathrm{GPa}$, in good 
agreement with other reports in the literature. However the values were dependent on femoral morphology and variations of $2.6 \mathrm{GPa}$ were obtained. Further analysis of our results indicated that the increase in the effective modulus was correlated with the increase in size and weight of the dogs. To our knowledge, such results have never before been quantified objectively in animal species. Since the Young's modulus for bovine, human and rabbit femurs are similar, it is clear that the Young's modulus of femoral cortical bone is not directly influenced by species. Thus, within a species this modulus might be modified by the height and weight of the animal. To suppress the potential effects of strain rate on measurement of mechanical parameters, we used a Young's modulus corrected to a strain rate of $0.00001 / \mathrm{s}$. This corrected stiffness was significantly lower for the Toy poodle than for the Doberman, indicating an actual difference between dogs according to their size.

The yield strength and ultimate strength were in good agreement with previously published data. Our average values were 174 and $251 \mathrm{MPa}$, respectively, and within the range of previously reported data, i.e., 108-172 MPa for yield strength (Bayraktar et al., 2004; Currey, 2004b) and up to $225 \mathrm{MPa}$ for ultimate strength (An et al., 1996; Ayers et al., 1996; Currey, 2004a; Currey et al., 1995; Lotz et al., 1991; Sedlin and Hirsch, 1966). The yield strength and ultimate strength were found to depend on dog characteristics since discrepancies of up to $\pm 20 \%$ were obtained. The ultimate strength $\sigma_{u}$ and strain energy density at ultimate failure $U_{u}$ for the Toy poodle were significantly lower than for the Poodle and German shorthaired pointer, indicating that the cortical bone material of the smallest dog differed from that of these other dogs.

Structural strength has been investigated with respect to plastic deformation and no robust correlations were found between stiffness and strength with passive material such as metallic alloys or polymers. However, in the present study, a strong relationship was found between ultimate strength and Young's modulus as well as between corrected ultimate strength and corrected Young's modulus. Such correlations between ultimate strength and stiffness have already been reported (Fyhrie and Vashishth, 2000; Yeni et al., 2004).

Bayraktar et al. (2004), working on mid diaphyseal cortical bone of the human femur, tested in uniaxial tension showed that yield strain had a very low variability and was independent of the elastic modulus. In our study, a relationship was demonstrated between yield strain and the effective elastic modulus of the mid diaphyseal femoral cortical bone of dogs in a three-point bending test $\left(P=0.001 ; r^{2}=0.25\right)$. These discrepancies could be related to the different species and to the different methods of mechanical testing (tensile vs. bending tests).

Investigation of the influence of different sites on the mechanical properties of femoral diaphyseal cortical bone revealed that bending tests in human specimens did not show any differences in elastic modulus between lateral, medial, cranial and caudal sites (Cuppone et al., 2004). On the other hand, medial bone was stiffer than caudal, cranial and lateral bones in horses (Spatz et al., 1996). Compressive tests on the canine femur produced greater stiffness in the lateral site than in the medial, caudal and cranial sites (Kenner et al., 1979). In our experiments, a higher value for the effective elastic modulus was found in the cranial site of the femoral diaphysis. These discrepancies could be linked to the different species and to the different methods of mechanical testing (compressive vs. bending tests). Some of the species variations might be due to differences in posture and locomotion of bipeds and quadrupeds, which lead to differences in bone loading (Schryver, 1978).

The dependence of bone strength on anatomical site was variable. In human specimens subjected to tensile loads, the ultimate tensile strength was greater in the lateral quadrant than in the cranial quadrant (Evans and Lebow, 1951). Compressive tests in ca- nine femurs showed that ultimate compressive strengths were highest in the lateral site (Kenner et al., 1979). In our study, we found that the yield strength at the medial site was greater than at the caudal site and the ultimate strength of the caudal site was lower than that of the medial and cranial sites.

The caudal cortex was less stiff and less strong than the cranial cortex. Similar findings were reported in the equine femur (Schryver, 1978), the sheep radius (Lanyon et al., 1979), the radius of horses (Riggs et al., 1993b) and the equine third metacarpal bones (Les et al., 1997). It is possible to interpret these observations in terms of safety factors (Riggs et al., 1993b). The dog femur, like many other limb bones, has a longitudinal, cranially convex curvature, suggesting cranio-caudal bending during locomotion. As suggested by Riggs et al. (1993b), axial compression superimposed on cranio-caudal bending tends to partially neutralise the longitudinal tensile strain in the cranial cortex and accentuate the longitudinal compression strains in the caudal cortex. An axial load on the femoral head in dogs induced tensile strains in the cranial cortex of the femur and compressive strains in the caudal cortex (Palierne, 2006). The lower Young's modulus of the caudal cortex will further accentuate bending and contribute to functional strains during locomotion (Riggs et al., 1993b). The amount of peak strain imposed on the cranial and caudal cortices of the femurs in the Palierne study (Palierne, 2006) was 1:1.69. This ratio was similar to that found on the sheep radius (Lanyon et al., 1979) and the difference between the two cortices may be considered as a safety factor for the bone (Lanyon et al., 1979). The ultimate strength of the medial cortex was also higher than for the caudal cortex. Similar results have been reported in the femur of horses subjected to bending tests (Schryver, 1978). As in the present study, the values of ultimate strength of the cranial and medial cortices were of the same order of magnitude. It is possible that the differences between quadrants were due to the orientation of the collagen in the various quadrants of the femur that has been related to differences in loading (Riggs et al., 1993a,b).

\section{Conclusions}

Given that canine femoral morphology shows obvious variability, our experimental protocol showed that the effective Young's modulus, yield strength and ultimate strength of diaphyseal cortical bone were dependent on femoral length and the site of harvesting (lateral, medial, cranial or caudal). Further studies on a larger number of femurs in each cluster are needed to extrapolate these results to the canine population as a whole.

\section{Conflict of interest statement}

None of the authors of this paper has a financial or personal relationship with other people or organisations that could inappropriately influence or bias the content of the paper.

\section{References}

An, Y.H., Kang, Q., Friedman, R.J., 1996. Mechanical symmetry of rabbit bones studied by bending and indentation testing. American Journal of Veterinary Research 57, 1786-1789.

Ayers, R.A., Miller, M.R., Simske, S.J., Norrdin, R.W., 1996. Correlation of flexural structural properties with bone physical properties: A four species survey. Biomedical Sciences Instrumentation 32, 251-260.

Barengolts, E.I., Curry, D.J., Bapna, M.S., Kukreja, S.C., 1993. Effects of endurance exercise on bone mass and mechanical properties in intact and ovariectomized rats. Journal of Bone and Mineral Research 8, 937-942.

Bayraktar, H.H., Morgan, E.F., Niebur, G.L., Morris, G.E., Wong, E.K., Keaveny, T.M., 2004. Comparison of the elastic and yield properties of human femoral trabecular and cortical bone tissue. Journal of Biomechanics 37, 27-35.

Behrens, B.A., Nolte, I., Bouguecha, A., Helms, G., Gerkhardt, E., Meyer-Lindenberg, A., 2006. Determination of the elastic properties of the compact bone in the femur of dogs. Deutsche Tierarztliche Wochenschrift 113, 24-27. 
Bonfield, W., Li, C.H., 1968. The temperature dependence of the deformation of bone. Journal of Biomechanics 1, 323-329.

Bonfield, W., Tully, A.E., 1982. Ultrasonic analysis of the Young's modulus of cortical bone. Journal of Biomedical Engineering 4, 23-27.

Boutros, C.P., Trout, D.R., Kasra, M., Grynpas, M.D., 2000. The effect of repeated freeze-thaw cycles on the biomechanical properties of canine cortical bone. Veterinary and Comparative Orthopaedics and Traumatology 13, 59-64.

Carter, D.R., Hayes, W.C., 1976. Bone compressive strength - Influence of density and strain rate. Science 194, 1174-1176.

Carter, D.R., Hayes, W.C., 1977. Compressive behavior of bone as a 2-phase porous structure. Journal of Bone and Joint Surgery - American Volume 59, 954-962.

Cuppone, M. Seedhom, B.B., Berry, E. Ostell, A.E. 2004. The longitudinal Young's modulus of cortical bone in the midshaft of human femur and its correlation with CT scanning data. Calcified Tissue International 74, 302-309.

Currey, J.D., 1988. The effect of porosity and mineral content on the Young's modulus of elasticity of compact bone. Journal of Biomechanics 21, 131-139.

Currey, J.D., 2004a. Incompatible mechanical properties in compact bone. Journal of Theoretical Biology 231, 569-580.

Currey, J.D., 2004b. Tensile yield in compact bone is determined by strain, postyield behaviour by mineral content. Journal of Biomechanics 37, 549-556.

Currey, J.D., Brear, K., Zioupos, P., Reilly, G.C., 1995. Effect of formaldehyde fixation on some mechanical properties of bovine bone. Biomaterials 16, 1267-1271.

Currey, J.D., Foreman, J., Laketic, I., Mitchell, J., Pegg, D.E., Reilly, G.C., 1997. Effects of ionizing radiation on the mechanical properties of human bone. Journal of Orthopaedic Research 15, 111-117.

Daugaard, H., Elmengaard, B., Bechtold, J.E., Soballe, K., 2008. Bone growth enhancement in vivo on press-fit titanium alloy implants with acid etched microtexture. Journal of Biomedical Materials Research - Part A 87, 434-440.

Evans, F.G., Lebow, M., 1951. Regional differences in some of the physical properties of the human femur. Journal of Applied Physiology 3, 563-572.

Fyhrie, D.P., Vashishth, D., 2000. Bone stiffness predicts strength similarly for human vertebral cancellous bone in compression and for cortical bone in tension. Bone 26, 169-173.

Jorgensen, P.H., Bak, B., Andreassen, T.T., 1991. Mechanical properties and biochemical composition of rat cortical femur and tibia after long-term treatment with biosynthetic human growth hormone. Bone 12, 353-359.

Kenner, G.H., Taylor, L.C., Park, J.B., 1979. Compressive strength of canine femur. Journal of Biomechanics 12, 519-526.

Lakes, R.S., 2004. Viscoelastic measurement techniques. Review of Scientific Instruments 75, 797-810.

Lanyon, L.E., Magee, P.T., Baggott, D.G., 1979. Relationship of functional stress and strain to the processes of bone remodeling - Experimental-study on the sheep radius. Journal of Biomechanics 12, 593-600.

Les, C.M., Stover, S.M., Keyak, J.H., Taylor, K.T., Willits, N.H., 1997. The distribution of material properties in the equine third metacarpal bone serves to enhance sagittal bending. Journal of Biomechanics 30, 355-361.

Linde, F., Norgaard, P., Hvid, I., Odgaard, A., Søballe, K., 1991. Mechanical-properties of trabecular bone - Dependency on strain rate. Journal of Biomechanics 24, 803-809.

Lotz, J.C., Gerhart, T.N., Hayes, W.C., 1991. Mechanical properties of metaphyseal bone in the proximal femur. Journal of Biomechanics 24, 317-329.

Markel, M.D., Sielman, E., Rapoff, A.J., Kohles, S.S., 1994. Mechanical properties of long bones in dogs. American Journal of Veterinary Research 55, 1178-1183.

Palierne, S., 2006. Quantification objective de la géométrie et du comportement biomécanique du fémur dans l'espèce canine: Application à quatre groupes morphologiques. Thesis, PhD dissertation, University of Toulouse.
Palierne, S., Mathon, D., Asimus, E., Concordet, D., Meynaud-Collard, P., Autefage, A., 2008. Segmentation of the canine population in different femoral morphological groups. Research in Veterinary Science 85, 407-417.

Paul, H.A., Bargar, W.L., 1986. Histologic changes in the dog femur following total hip replacement with current cementing techniques. Journal of Arthroplasty 1, $5-9$

Rice, J.C., Cowin, S.C., Bowman, J.A., 1988. On the dependence of the elasticity and strength of cancellous bone on apparent density. Journal of Biomechanics 21, 155-168.

Riggs, C.M., Lanyon, L.E., Boyde, A., 1993a. Functional associations between collagen fiber orientation and locomotor strain direction in cortical bone of the equine radius. Anatomy and Embryology 187, 231-238.

Riggs, C.M., Vaughan, L.C., Evans, G.P., Lanyon, L.E., Boyde, A., 1993b. Mechanical implications of collagen fiber orientation in cortical bone of the equine radius. Anatomy and Embryology 187, 239-248.

Romanus, B., 1974. Physical properties and chemical content of canine femoral cortical bone in nutritional osteopenia: Its reversibility and the effect of fluoride. Acta Orthopaedica Scandinavica Suppl. 155, 1-101.

Schryver, H.F., 1978. Bending properties of cortical bone of horse. American Journal of Veterinary Research 39, 25-28.

Sedlin, E.D., Hirsch, C., 1966. Factors affecting the determination of the physical properties of femoral cortical bone. Acta Orthopaedica Scandinavica 37, 29-48.

Skurla, C.P., Pluhar, G.E., Frankel, D.J., Egger, E.L., James, S.P., 2005. Assessing the dog as a model for human total hip replacement. Analysis of 38 canine cemented femoral components retrieved at post-mortem. The Journal of Bone and Joint Surgery. British Volume 87, 120-127.

Smith, J.W., Walmsley, R., 1959. Factors affecting the elasticity of bone. Journal of Anatomy 93, 503-523.

Søballe, K., Hansen, E.S., Rasmussen, H.B., Jorgensen, P.H., Bunger, C., 1992. Tissue ingrowth into titanium and hydroxyapatite-coated implants during stable and unstable mechanical conditions. Journal of Orthopaedic Research 10, 285-299.

Spatz, H.C., OLeary, E.J., Vincent, J.F.V., 1996. Young's moduli and shear moduli in cortical bone. Proceedings of the Royal Society of London Series B - Biological Sciences 263, 287-294.

Turner, C., 1993. Age, bone material properties, and bone strength. Calcified Tissue International 53, S32-S33.

Turner, C.H., Burr, D.B., 1993. Basic biomechanical measurements of bone - A tutorial. Bone 14, 595-608.

Turner, C.H., Burr, D.B., 2001. Experimental techniques for bone mechanics. In: Cowin, S.C. (Ed.), Bone Mechanics Handbook. CRC Press, Boca Raton, pp. 7-1-735 .

Vahey, J.W., Lewis, J.L., Vanderby, R., 1987. Elastic moduli, yield stress, and ultimate stress of cancellous bone in the canine proximal femur. Journal of Biomechanics 20, 29-33.

Vestermark, M.T., Bechtold, J.E., Swider, P., Soballe, K., 2004. Mechanical interface conditions affect morphology and cellular activity of sclerotic bone rims forming around experimental loaded implants. Journal of Orthopaedic Research 22, 647-652.

Wergedal, J.E., Sheng, M.H., Ackert-Bicknell, C.L., Beamer, W.G., Baylink, D.J., 2005. Genetic variation in femur extrinsic strength in 29 different inbred strains of mice is dependent on variations in femur cross-sectional geometry and bone density. Bone 36, 111-122.

Yeni, Y.N., Dong, X.N., Fyhrie, D.P., Les, C.M., 2004. The dependence between the strength and stiffness of cancellous and cortical bone tissue for tension and compression: Extension of a unifying principle. Bio-Medical Materials and Engineering 14, 303-310. 